\title{
Influence of undefined modes of movement on instantaneous redistribution of normal reactions of quarry dump truck tires
}

\author{
Mikhail Dadonov ${ }^{1 *}$, Alexander Kulpin ${ }^{1}$, Evdokia Kulpina ${ }^{2}$, Valery Borovtsov ${ }^{3}$, and Gulzira \\ Mukasheva $^{4}$ \\ 1,T.F. Gorbachev Kuzbass State Technical University, Department of Vehicle Operation, 650000, \\ Kemerovo, 28 Vesennyaya st., Russian Federation \\ ${ }^{2}$ T.F. Gorbachev Kuzbass State Technical University, Department of production management, \\ 650000, Kemerovo, 28 Vesennyaya st., Russian Federation \\ ${ }^{3}$ T.F. Gorbachev Kuzbass State Technical University, Department of foreign languages, 650000, \\ Kemerovo, 28 Vesennyaya st., Russian Federation \\ ${ }^{4}$ Kazakh Humanitarian Law Innovative University, Department of Information and Technical \\ Sciences
}

\begin{abstract}
Reducing the costs of rock transportation in mining is one of the most important tasks. One of the reserves for solving this issue is a more complete use of the service life of quarry dump trucks tires, since their operation takes place in heavy mining and climatic conditions and this significantly reduces the life of tires. The life of tires depends on many factors: speed of movement, compliance with the recommended air pressure in the tire, ambient air temperature, but the main thing is the change in the normal load on the wheel, which depends on the redistribution of the quarry dump truck weight in case of non-linear movement and on the longitudinal profile of the quarry road. In real conditions, the quarry dump truck moves unevenly due to the complexity of the road - either braking or acceleration occur. This article allows you to evaluate the impact of non-linear modes of quarry dump truck movement on the instant redistribution of normal tire reactions and take into account peak loads on wheels during acceleration and braking in the regular cycle. This will allow you to control the load on the tires directly by cargo amount in the quarry dump truck and thereby increase the life of the tires and their reliability, as well as reduce the cost of transporting the rock mass in real operating conditions.
\end{abstract}

\section{Introduction}

The efficiency of the transport process in open mining consists in the efficiency of the each unit operation of technological and auxiliary transport and the rational use of the production and technical base and human resource. Mining causes difficult operating conditions for any type of process transport equipment, varying within wide mining and climatic limits.

* Corresponding author: dadonovmv@,kuzstu.ru 
These conditions, in turn, determine the resource and performance of transport, its elements and systems [1-7].

Large-sized and oversized tires of modern quarry dump trucks are vary important and extremely expensive elements. They provide close dynamic communication in the system "quarry dump truck - quarry road," the safety of the quarry dump trucks movement depends on technical condition of this system. At the same time, with all the variety of operating conditions, the service life of the tires is largely determined by the load, which can differ significantly, depending on the place of installation, even within the limits of one self-driven truck $[8,9]$. In the materials of our article [8], the possible static redistribution limits of loads were determined and real road conditions were revealed, under which more than half of the weight of the quarry dump truck can fall on one wheel. In addition to static weight redistribution depending on quarry dump truck position in space, an important role is played by the process of instantaneous change of loads on tires during movement, which forms during the transport cycle some additional dynamic component, the value of which must be known. Aerodynamic factors arising in the interaction of the ambient air with the surface of the quarry dump truck and affecting the dynamic redistribution of loads were analyzed in our work [9]. Identification of movement modes unknown influence significance on instantaneous redistribution of normal reactions of quarry dump trucks tires is the purpose of this article.

The movement of quarry dump trucks in real conditions is extremely rarely uniform. As a rule, the transport cycle consists of accelerations and decelerations combination. At the same time, both accelerated and delayed movement leads to an additional redistribution of weight between the axles of the quarry dump truck [10-13].

Figure 1 shows a diagram of the forces and reactions acting on the quarry dump truck with accelerated movement.

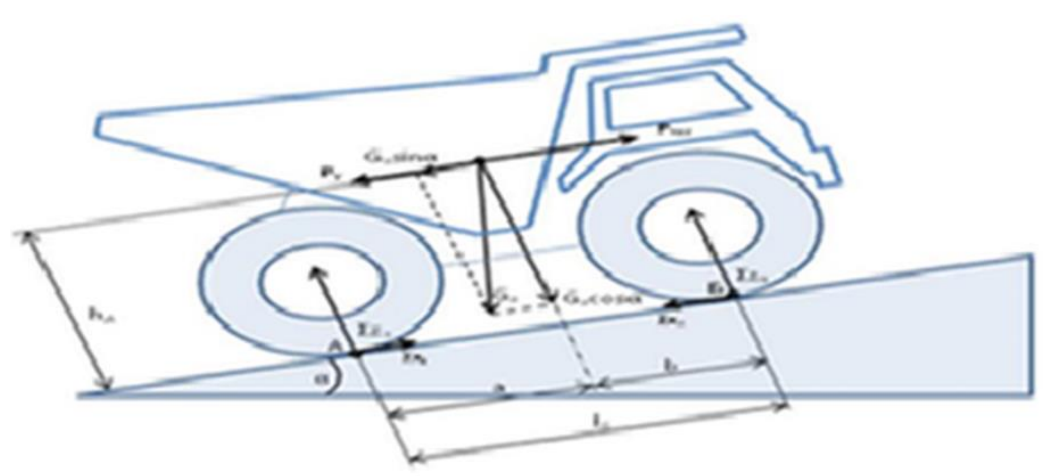

Fig. 1. Forces acting on the quarry dump truck when accelerating.

$\mathrm{G}_{\mathrm{a}}$ - weight of the quarry dump truck, $\mathrm{H}$, equal to the sum of the own weight of the quarry dump truck and the actual weight of the cargo;

$\mathrm{P}_{\mathrm{y}}-$ the force of the quarry dump truck inertia when accelerating, $\mathrm{H}$;

$\mathrm{P}_{\mathrm{tf}}-$ traction force of the quarry dump truck, $\mathrm{H}$;

$\Sigma \mathrm{z}_{\mathrm{r}}, \Sigma \mathrm{z}_{\mathrm{f}}$ - sum of normal reactions of rear and front wheels respectively, $\mathrm{H}$;

$\Sigma \mathrm{x}_{\mathrm{r}}, \Sigma \mathrm{x}_{\mathrm{f}}-$ sum of longitudinal reactions of rear and front wheels respectively, $\mathrm{H}$;

$\mathrm{h}_{\mathrm{h}}$ - the quarry dump truck gravity center height, $\mathrm{m}$;

$\mathrm{l}_{\mathrm{b}}$ - distance between the front and rear axles of the quarry dump truck, m; 
a - distance between the gravity center and the rear axle of the quarry dump truck, $\mathrm{m}$;

$\mathrm{b}$ - the distance between the gravity center and the front axle of the quarry dump truck, m;

$\alpha$ - corner of the longitudinal profile of the quarry road, rad.;

$+\alpha-$ movement to climb;

$-\alpha$-descent movement.

In the process of acceleration, an inertia force is generated directed against the line of the quarry dump truck motion. At the same time, the load on the wheels of the quarry dump truck is redistributed from the front to the rear [14-17]. I.e. sum of normal reactions of front wheels decreases, while sum of normal reactions of rear wheels increases by value of $\Delta z_{\mathrm{p}}$. The maximum amount of redistribution will correspond to the maximum force of traction (1) realized on the driving wheels, but may be limited by the condition of wheel engagement with the road (2).

$$
\begin{aligned}
& \Delta z_{P y}^{\max }=\frac{h_{h}}{l_{b}}\left[\frac{\mathrm{M}_{t f}^{\max }}{r_{d}}-G_{a}(f \pm \alpha)-k F V_{a}^{2}\right],[H], \\
& \Delta z_{P y f}^{\max }=\frac{h_{h}}{l_{b}}\left\{G_{a}\left[\varphi \frac{b}{l_{b}}-(f \pm \alpha)\right]-k F V_{a}^{2}\right\},[H] .
\end{aligned}
$$

where $\mathrm{f}$ - is rolling resistance coefficient;

$\mathrm{k}$ - air resistance coefficient, $\mathrm{Hc} 2 / \mathrm{m} 4$;

$\mathrm{F}$ - midship cross-section area, $\mathrm{m} 2$;

$\mathrm{V}_{\mathrm{a}}$ - is the speed of the quarry dump truck, $\mathrm{m} / \mathrm{s}$,

Using the example of the BelAZ-75131 auto dump, calculations made it possible to establish that the most significant factors affecting the redistribution of loads during the accelerated movement of the quarry dump truck are the longitudinal profile of the quarry road, the road pavement condition and the weight of the load in the body (Fig. 2 - 4).

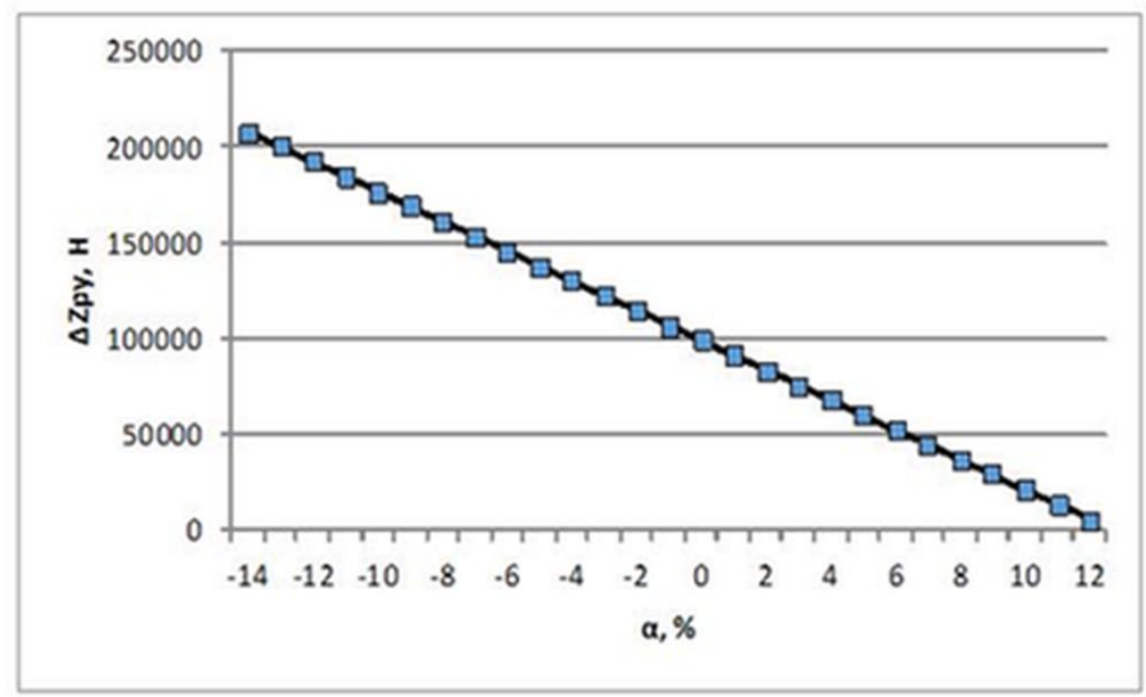

Fig. 2. Dependence of the value of the redistributed weight of the quarry dump truck on the longitudinal slope of the road during acceleration. 


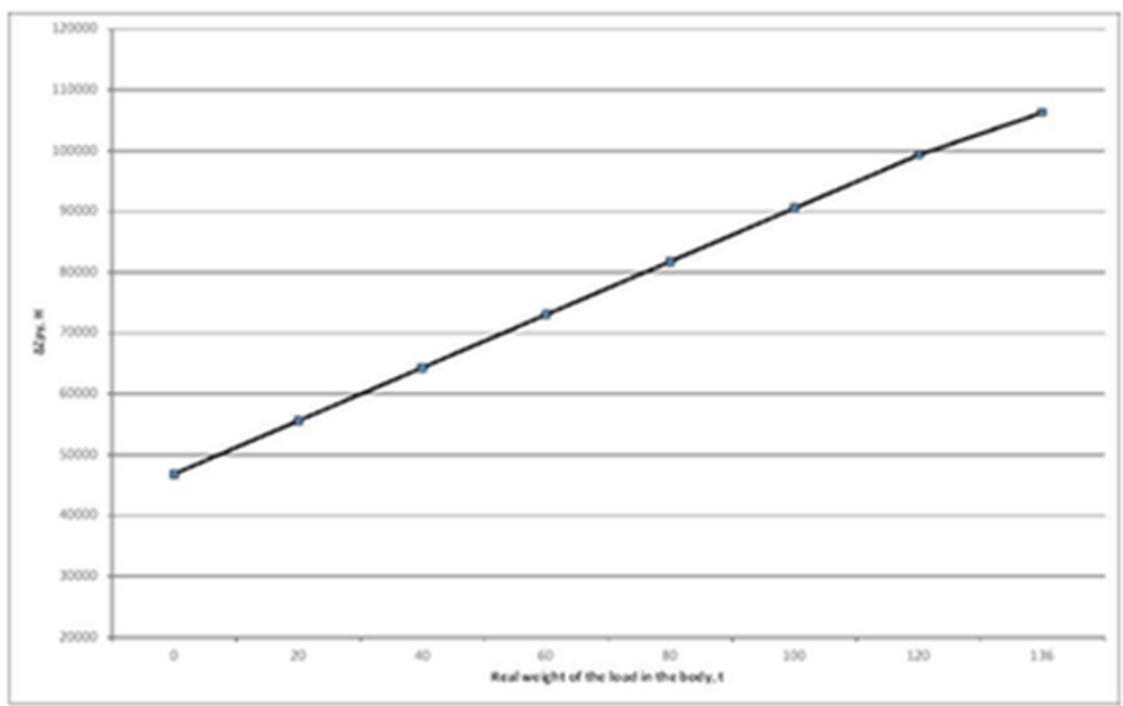

Fig. 3. Dependence of the value of the redistributed weight of the quarry dump truck on the actual weight of the load in the body during acceleration.

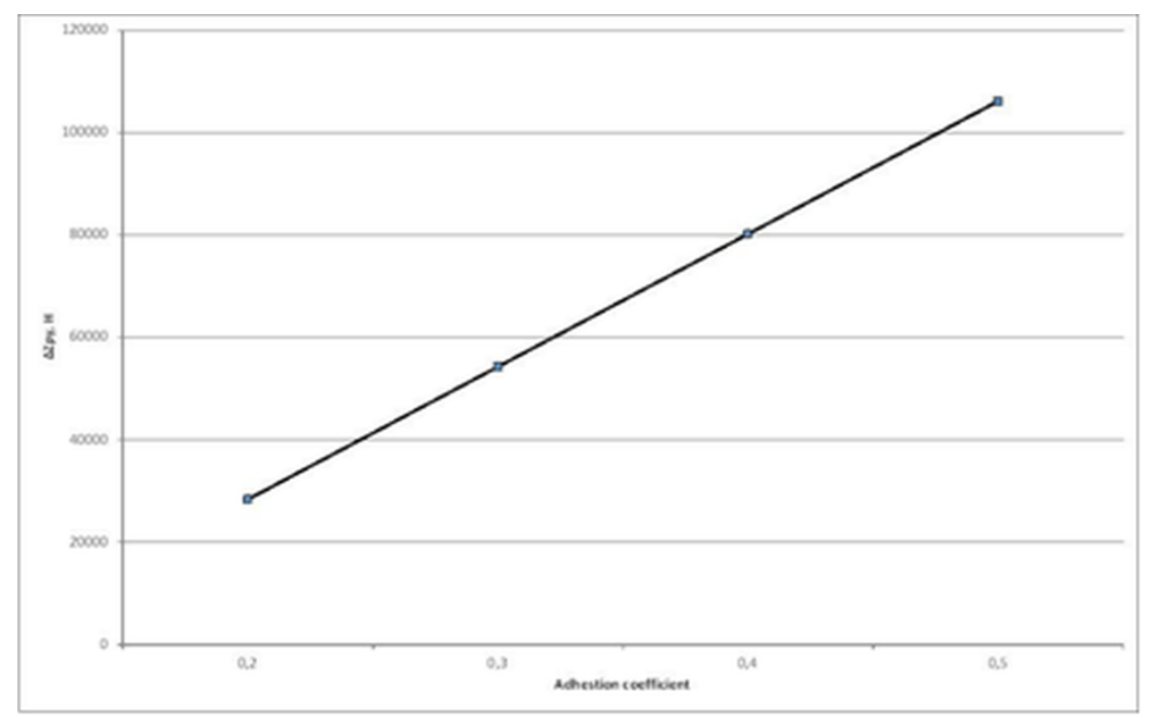

Fig. 4. Dependence of the value of the redistributed weight of the quarry dump truck on the adhestion coefficient during acceleration. 


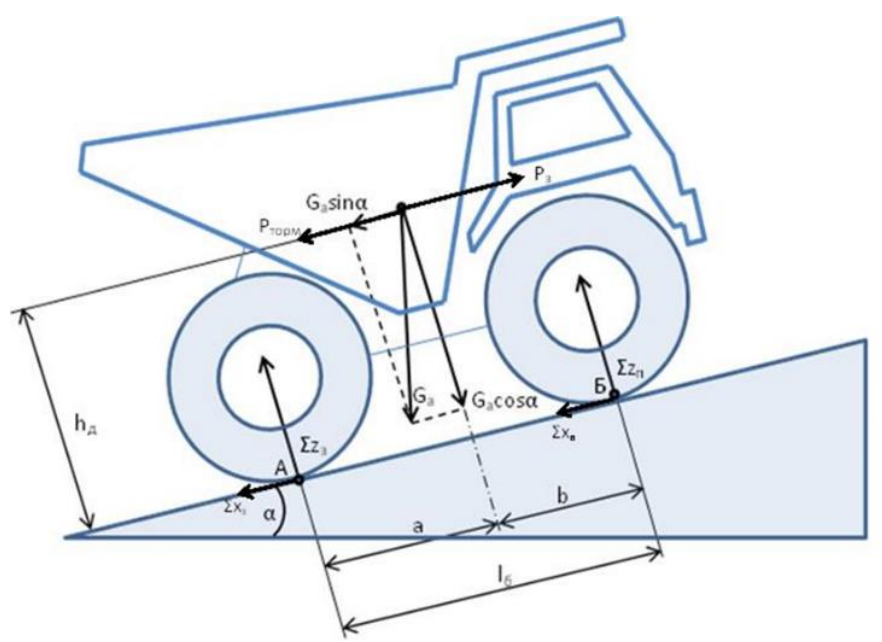

Fig. 5. Forces acting on the quarry dump truck when braking.

$\mathrm{P}_{\mathrm{r}}$ - quarry dump truck inertia force of at delay, $\mathrm{H}$;

$\mathrm{P}_{\mathrm{br}}-$ braking force of the quarry dump truck, $\mathrm{H}$.

During braking, inertia force is generated, which is directed along the quarry dump truck movement line (Fig. 5). At the same time, the load on the wheels of the quarry dump truck is redistributed from the rear to the front [18-25]. I.e. sum of normal reactions of rear wheels decreases, and sum of normal reactions of front wheels increases by value $\Delta z_{\mathrm{Pr}}$.

$$
\Delta z_{P r}=\frac{h_{h}}{l_{b}}\left[G_{a}(\varphi+f \pm \alpha)+k F V_{a}^{2}\right],[H]
$$

During braking, longitudinal slopes, wheel-road adhesion conditions and weight of cargo in the body were also the most significant factors (Fig. 6 - 8). The diagrams were obtained using the example of the BelAZ-75710.

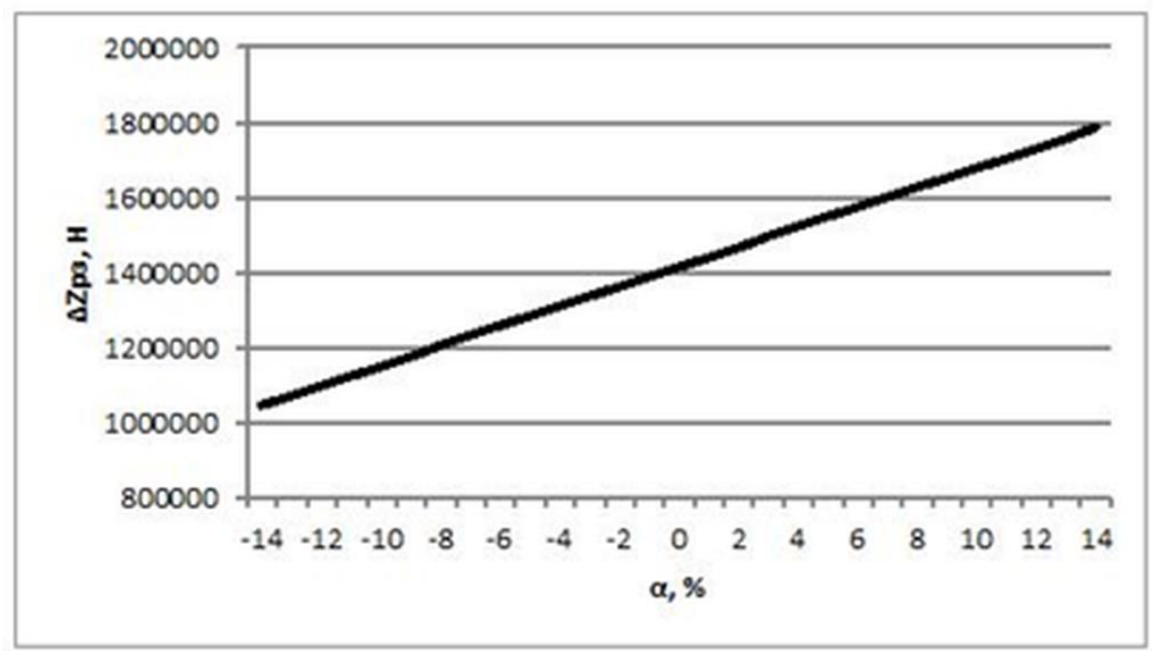

Fig. 6. The value changes of the redistributed weight when the quarry dump truck is slowed down depending on the longitudinal slope of the road. 


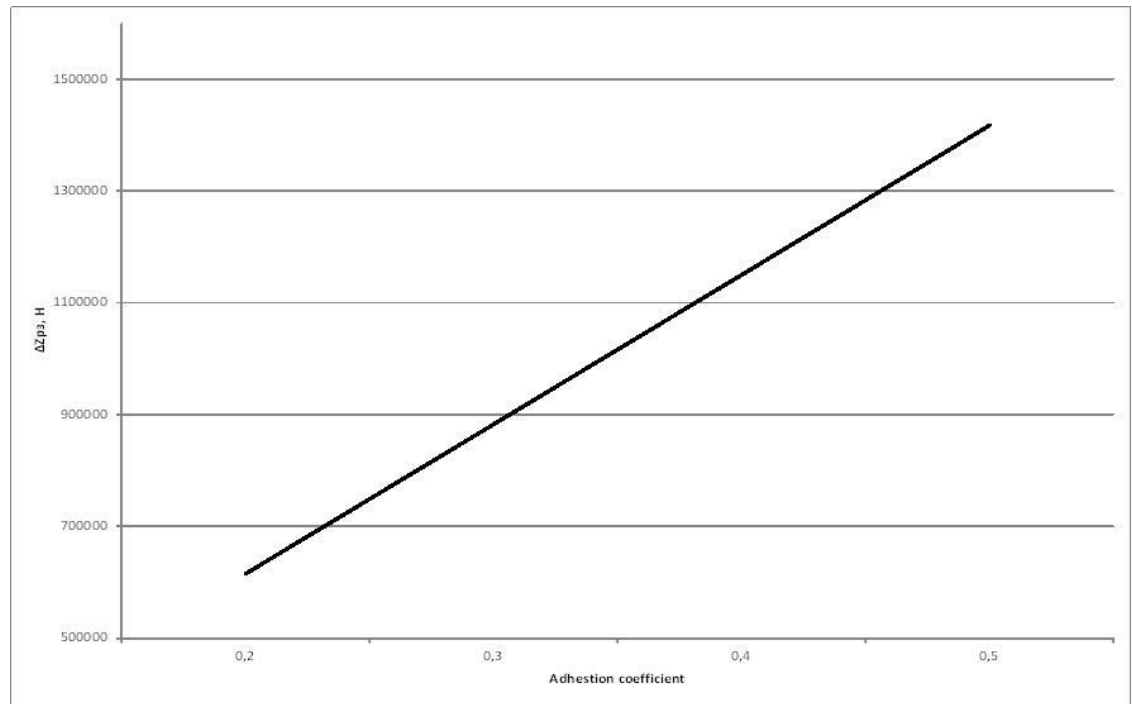

Fig. 7. The value changes of the redistributed weight when the quarry dump truck is slowed down from the grip factor.

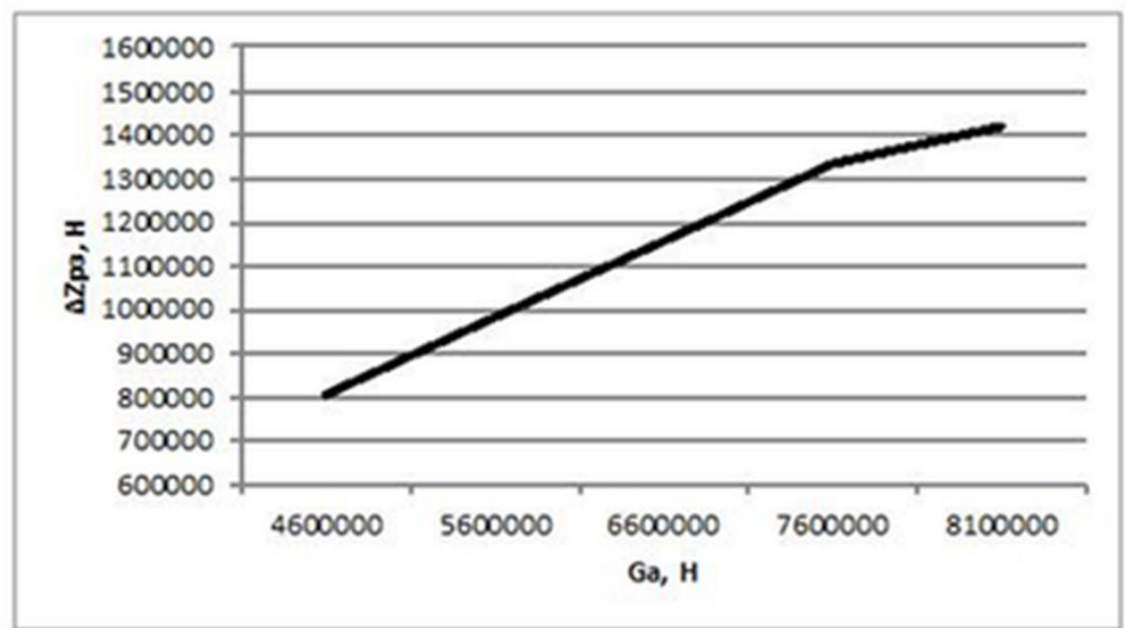

Fig. 8. The value dependence of the redistributed weight at deceleration of the quarry dump truck on the weight of the self-dump truck with the load.

Analysis of the obtained dependencies makes it possible to conclude that it is necessary to take into account periods of accelerated and delayed movement in the flight cycle in order to determine instantaneous peak and average loads arising on each wheel.

The work is executed within the limits of the complex scientific and technical program of a full innovative cycle "Development and introduction of a complex of technologies in areas of exploration and extraction of solid minerals, maintenance of industrial safety, bioremediation, creation of new products of deep processing from coal raw materials at consecutive decrease in ecological impact on environment and risks for population life" (CSTP "Clean coal - Green Kuzbass") on event 2.5 "Development and creation of an autonomous shuttle-type dump truck with carrying capacity of 220 tons 
(JUPITER project)", with participation of T.F. Gorbachev Kuzbass State Technical University in terms of research, development and technological works.

\section{References}

1. G.M. Dubov, D.S. Trukhmanov, A.A. Chegoshev, V.E. Ashikhmin, E3S Web Conf., 41, 03008 (2018)

2. G.M. Dubov, D.S. Trukhmanov, S.A. Nokhrin, IOP Conf. Series: Earth and Environ. Sci., 459, 042059 (2020)

3. D.M. Dubinkin Mining Equipment and Electromechanics. 4, 59 (2020)

4. D. Dubinkin, V. Aksenov, M.Tyulenev, S. Markov, Journal of mining and geotechnical engineering. 4, 42 (2020)

5. D.M. Dubinkin, A.B. Kartashov, G.A. Arutyunyan, N.V. Buzunov, K.P. Sorokin, A.V. Yalyshev, Mining Equipment and Electromechanics. 6, 31 (2020)

6. D.V. Stenin,Mining Equipment and Electromechanics. 6, 146 (2019)

7. A. Kartashov, B. Kositsyn, G. Kotiev, S. Nazarenko, D. Dubinkin. E3S Web of Conferences. 174, 03009 (2020)

8. M. Dadonov, A. Kulpin, O. Ostanin, E. Suleimenov,E3S Web of Conferences 105, 03009 (2019)

9. M. Dadonov, A. Kulpin, V. Borovtsov, A. Zhunusbekova, E3S Web of Conferences 174, 03018 (2020)

10. A.G. Kulpin, D.V. Stenin, E.E. Kultayev, E.E. Kulpina, V.A. Borovtsov Influence jf service conditions of quarry dump trucks on the thermal state large-size tires(Coal in the 21st Century: Mining, Processing and Safety 2016)

11. A.G. Kulpin, D.V. Stenin, E.E. Kultayev, E.E. Kulpina, V.A. Borovtsov (Coal in the 21st Century: Mining, Processing and Safety ,2016)

12. D.V. Stenin, N.A Stenina, A.A Bakanov (Coal in the 21st Century: Mining, Processing and Safety (2016)

13. X. Yang, O. Olatunbosun, D. Garcia-Pozuelo, E Bolarinwa, SAE Technical Papers (2015)

14. Q. Sunqing, D. Junxiu, Ch. Guoxu, Lubricating Science, 11:3, 165 (1999)

15. A. A Samarskii, V. A Galaktionov, S. P Kurdiumov, A.P. Mikhailow, Blow-up in quasilinear parabolic equations (Berlin, Walter de Gruytel, 1995)

16. A. Abramovich, E Pudov, E Kuzin, E3S Web of Conferences, 21, 01011 (2017)

17. A Kvasova, B Gerike, E Murko, D Skudarnov. E3S Web of Conferences, 21, 03016 (2017)

18. F. Zhang, Z., Gu, S. Zhang, X. Ma, Zhu, Y. ZhendongyuChongji, Journal of Vibration and Shock, 35, 17, 71 (2016)

19. T.H. Langer, T.K. Iversen, O.O. Mouritsen, M.K. Bak, M.R. Hansen, International Journal of Vehicle Design, 65, 2, 222 (2014)

20. J. Meech, J. Parreira, IFAC Proceedings Volumes, 15:1, 142 (2013)

21. Y. Li, W.Y. Liu, S. Frimpong, Engineering Failure Analysis, 23, 55 (2013)

22. R. Larson, J. Cuadrado, SAE International Journal of Commercial Vehicles, 5:1, $101(2012)$

23. K. Pal, T. Das, Polymer Engineering and Science, 48:12, 2410 (2008)

24. T. Eguchi, T. Muro, 15th International Conference of the International Society for Terrain Vehicle Systems (2005)

25. P.F. Knights, A.L. Boerner, Mining Engineering, 53:8, 51 (2001) 